\title{
Covid-19, Harassment and Social Media: A Study of Gender-Based Violence Facilitated by Technology During the Pandemic
}

\author{
Mochamad Iqbal Jatmiko $^{1^{*}}$, Muh. Syukron², Yesi Mekarsari ${ }^{3}$ \\ ${ }^{1,3}$ Department of Sociology, Faculty of Social and Political Sciences, \\ Gadjah Mada University, Indonesia \\ Email: mochamad.iqbal.j@mail.ugm.ac.id \\ Email: yesi.mekarsari@mail.ugm.ac.id \\ ${ }^{2}$ Department of Sociology, University of Missouri at Columbia, Missouri, USA. \\ Email:mswzv@umsystem.edu
}

\begin{abstract}
The transition of all individual activities in the home gives rise to two forms of violence against women: domestic violence and online sexual violence. Specifically, this article argues that independent quarantine during the COVID-19 pandemic has shifted the orientation of community sexual violence to technology-facilitated sexual abuse. Social media networks have become a trajectory of changes in sexual violence that was initially physical into online sexual violence. This research uses a qualitative method with a case study approach to understanding online sexual violence. The data presented here refer to the experiences of four survivors with different backgrounds and stories. The results show that technology has facilitated digital abuse, which impacts a series of dangerous behaviors experienced in social media. As part of social media users, women are very vulnerable to experiencing online sexual violence from personal relationships, boyfriends, friends, and relatives. Space and time in the real world folded in such a way as to provide opportunities for the reality of virtual networks to become a realm of gender-based violence. At the same time, social media's neutrality then becomes a means of supporting gender inequality.
\end{abstract}

Keywords: sexual violence, online harassment, gender-based violence, social media, COVID-19

Paper type: Research paper

*Corresponding author: mochamad.iqbal.j@mail.ugm.ac.id Submitted: 2020-08-01; Accepted: 2020-10-29; Published: 2020-10-30

Cite this document: Jatmiko, Mochamad Iqbal, Muh. Syukron, and Yesi Mekarsari. (2020). Covid-19, Harassment and Social Media: A Study of Gender-Based Violence Facilitated by Technology During the Pandemic. The Journal of Society and Media, 4(2), 319-347. DOI: 10.26740/jsm.v4n2.p319-347 


\section{INTRODUCTION}

The pandemic coronavirus disease (COVID-19) has radically changed individuals' lives and society's structure. No one can predict the long-term implications and consequences of the COVID-19 pandemic (Mazza et al. 2020). Strict steps in managing public health to control an epidemic have been carried out throughout the country, such as lockdowns, working/studying from home, and social distancing. At the same time, individuals are required to stay and carry out all activities in the house throughout the day, according to instructions specified by the government. The ongoing policy of individual quarantine turns out to significantly stimulate social, economic, and psychological consequences.

A recent study began to expose the impact of the COVID-19 pandemic on gender inequality that underlies cases of violence against women. Some academics also revealed that there was an increase in reports of quarantine violence for women and children (van Gelder et al. 2020; John et al. 2020). The limited space for individuals due to independent quarantine drives the risk of preexisting vulnerabilities, especially in intimate partner violence (Garcia-Moreno et al. 2006). The transition of all activities at home increases the intensity of encounters with private partners. The house turns into a dangerous place for victims of domestic violence because it places women as objects of violence (Mazza et al. 2020).

Women tend to be at risk of being sexually and physically abused by intimate partners or non-partners in their lives; almost one-third of women in the world (Knaul, Bustreo, and Horton 2020). The United Nations Population Fund estimates that social restrictions under the six-month ongoing COVID-19 pandemic could result in an estimated 31 million additional cases of gender-based violence globally (Mahase 2020). Not much different from Indonesia, evidence of gender-based violence jumped dramatically during the coronavirus outbreak. According to The Women's Association for Justice and Legal Aid (LBH-APIK), from March to April 2020, there were 97 reported cases. Cases of gender-based violence still receive the most data, including evidence of domestic violence (33 cases), online gender-based violence (30 cases), sexual harassment (8 cases), rape (3 cases), and dating violence ( 7 cases).

In some cases, online gender-based violence acts show increasing significance. Even though the percentage of online gender-based violence cases in 


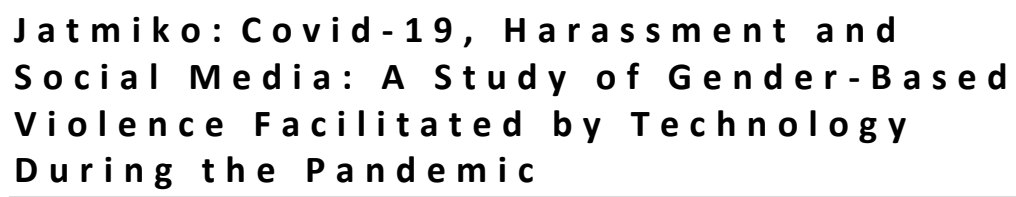

Indonesia during the pandemic is relatively low, the number of cases has increased in the last three years. Internet access has changed the pattern of interpersonal relations, which determines the norms in acting and interacting (Zhong, Kebbell, and Webster 2020). Digital technology devices have become a feature of contemporary society, especially among adolescents (Henry and Powell 2015).

As noted by Websindo (2019), the total number of social media users reached 150 million users with vulnerable ages between 18 and 34 years. Supported by the duration of excessive use of Indonesian social media for 7 hours 59 minutes (Ramadhan 2020) is one of the triggering factors of online harassment through mobile devices. The progress of the digital world has facilitated genderbased violence in the virtual realm so that it has become a crucial issue that requires special attention (Barak 2005; Kowalski and Limber 2007; Marwick and Miller 2014; Rodríguez-Darias and Aguilera-Ávila 2018).

Gender-based violence in social media networks has indeed attracted the attention of the public and academics in the past decade (see Ojanen et al. 2014). Much literature discusses online gender-based violence in several countries. The majority focus on experiences and forms of online sexual abuse (Barak 2005; Beech et al. 2008; Burke et al. 2011; Franklin 2014; Ging and Siapera 2018; Henry and Powell 2014, 2018; Kavanagh and Brown 2019; Powell 2010; Rodríguez-Darias and Aguilera-Ávila 2018; Shariff and DeMartini 2015; Vitis and Gilmour 2017) and discourses that based on decision making in public policy (Mena-Rodriguez and Velasco-Martínez 2017). Until now, there is still limited research that explores in-depth online gender-based violence in the Indonesian context, especially in the situation of the COVID-19 pandemic. Therefore, the uniqueness of this study relates to the contextual condition in Indonesia and explores the susceptibility of women to gender-based abuse online. Where women's vulnerability to physical gender-based violence during the quarantine of the COVID-19 pandemic has indeed increased, but online gender-based violence has increased more significantly.

This article seeks to enrich the preexisting literature by focusing on online gender-based violence rife during the pandemic and exploring the experiences of 
victims of online sexual abuse. Specifically, the authors explore survivors' narratives that openly, with an exclusive agreement, reveal their personal experiences. Based on the focus of the study, this article raises some questions, 1) how to project the experiences of victims of sexual violence online; 2) how technology facilitates online gender-based violence in a pandemic crisis. Throughout this article, the author departs from many perspectives of victims and simultaneously elaborates on a variety of relevant literature. The findings are expected to provide a general basis for the threats and implications of online gender-based violence against victims so that they can offer reflective solutions to developing more inclusive policies.

\section{METHOD}

Taking the context of Indonesia, this research is part of a qualitative research project that examines online gender-based violence against young girls during the COVID-19 pandemic in Indonesia. The case study approach using to explore and broaden sociological understanding of the phenomenon of online sexual harassment in the digital era (see Buiten 2020; Dodge and Spencer 2018; Fairbairn and Spencer 2018; Rodríguez-Darias and Aguilera-Ávila 2018; Shokooh Valle 2020). The chronology of the informants' experiences is the primary source of field data. The choice of method used has gone through several other considerations, such as data collection ethics, guaranteed anonymity to protect the identity of informants, and the interview process, which was carried out carefully by adjusting the socio-psychological conditions of the victim.

This research has been conducted for five months, from January to June 2020, since the COVID-19 pandemic in Indonesia. There are two techniques for selecting informants-first, a purposive technique to choose subjects that fit the research theme. Researchers conducted digital observations on social media Twitter, Telegram, and Instagram on several fake accounts that spread pornographic content or share non-consensual sexual images. From the results of digital observations, through the checking and deepening stage assisted by the team, the author obtained several informants from the screenshot of the victim's social media account, deliberately included by the fictional account admin. Second, the snowball technique is done manually through general communication media to expand further informant searches. 
Jat miko: Covid-19, Harassment and

Social Media: A Study of Gender-Based

Violence Facilitated by Technology

During the Pandemic

Based on this process, four victims were willing to be the subject of the informants in this study. All informants were young women aged 18-23 years spread across three provinces, namely Jakarta, Yogyakarta, and Surabaya. The general criteria for informants refer to women who have experienced online gender-based violence during the COVID-19 pandemic in Indonesia, to be precise, starting in January 2020. The reason for choosing these informants is to find out and explore cases of gender-based violence online during the COVID-19 pandemic. The narrative that is conveyed from the perspective of the victim expects to provide a projection of the research issue so that it can produce knowledge about shifts in sexual harassment or gender-based violence.

Table 1

List of Research Informants

\begin{tabular}{llll}
\hline Name (Initial) & Age & Profession & Domicile \\
\hline BL & 23 years old & Model & Jakarta \\
JM & 20 years old & Model/ College Student & Jakarta \\
MP & 18 years old & College Student & Surabaya \\
AC & 21 years old & Online Entrepreneur/ SPG & Yogyakarta \\
\hline
\end{tabular}

Data collection was carried out through indirect semi-structured interviews due to independent quarantine regulations. Researchers use several communication media, such as telephone networks, Video Call WhatsApp applications, and discussions through Google Meet. All verbal data is recorded and transcribed, except for parts that the informants think are inappropriate to include and sensitive expressions. Field data is then passed through the coding phase and grouped into one issue to be analyzed using a theoretical dromology framework from Paul Virilio to explore the study of online gender-based violence.

\section{RESULTS AND DISCUSSION}

\section{a. Social Media And Gender-Based Violence.}

The rapid expansion of the use of the internet and communication technology has resulted in significant changes, where social interaction is not only mediated by technology but increasingly relies on technology. However, as the use of the internet and information technology has affected an entire person's life, 
concerns about online threats have expanded to include various online sexual harassment. The current globalization increases the use of the internet globally and influences the emergence of online gender-based violence (Henry and Powell 2015, 2016; Zhong et al. 2020). The participation of women and children in the online space has been marked by concerns about their safety, especially the problem of online harassment and their vulnerability to online sexual predators (Barnes 2006; Jane 2014; Shade 2007; Vitis and Gilmour 2017).

In general, violence against women can be defined as gender-based acts of violence that result in physical, sexual-psychological damage, and suffering against women, including arbitrary deprivation in general or in private life (Cuklanz 2000; Kappler 2012). In contrast, sexual violence focuses more specifically on unwanted sexual behavior (physical or non-physical) directed at others, regardless of the relationship between the perpetrator and the victim. However, the term online sexual violence cannot be generalized in the real culture of violence because it does not accurately reflect the location of technological mediation in acts of sexual abuse, which is more widely open than in the past (Gundersen and Zaleski 2020; Zaleski et al. 2016). Therefore, the complexity of the issue of online gender-based violence that occurs in society must see in a culture of technology and more meaningful social discourse.

The utopian vision of digital technology that was once promoted as a new, democratic public space guaranteeing freedom of expression turned out to experience gender inequality similar to the real world. Social media is changing to strengthen old forms of gender inequality and improve them in new ways so that abuse can multiply (Henry and Powell 2015; Lewis, Rowe, and Wiper 2016; Litchfield et al. 2018). The justification of online sexual harassment is also inseparable from the hegemonic masculinity institutionalized in virtual public spaces. The patriarchal cultural dimension manifested as a disciplining subject to express gender hierarchies in the social-technological landscape. The idea of hegemonic masculinity then fosters the perception of social media that men will be male when committing gender-based violence as an acceptable natural act. The normality of violence against women can ultimately free men from the mistakes of online rape and other sexually aggressive behavior in the community (Klein 2005; Miller and Marshall 1987). 
Jat miko: Covid-19, Harassment and

Social Media: A Study of Gender-Based

Violence Facilitated by Technology

During the Pandemic

Technological developments that create social media or virtual networks weaken women by positioning them as objects of violence. Adolescent girls who are part of social media users are ultimately vulnerable to the risk of online crime. As Zhong, Kebbell, and Webster (2020) argue, which states two categories of online crime threats; first, pure cybercrime is a violation aimed at hardware or software. Secondly, cybercrimes supported by technology are legal violations aided by the internet. This type of crime in cyberspace is receiving attention because many women report incidents of online gender-based violence, such as cyberstalking, rape videos, online sex coercion, porn revenge, doxing, and violence facilitated by technology (Henry, Flynn, and Powell 2015; Jane 2018).

This phenomenon is indeed relatively new in some countries, especially in studies in Indonesia, although sexual violence facilitated by technology and online aggression against women has been reported since the early stages of internet growth (Henry et al. 2015; McCormick and McCormick 1992). However, these practices are essential to reconsider the role of contemporary technology because they change and strengthen gender-based violence. On the other hand, big data capabilities that extend the life of digital content and algorithm in search engines can easily link to the victim's name. Social media, at least, acts as a force multiplier that allows enormous negative impacts on victims beyond the dangers of real-world sexual violence (Williams 2006; Yar 2005).

\section{b. Narrative Of Online-Based Sexual Violence Victims}

This section describes the experience of the victim to obtain a brief description of sexual violence. We expose certain parts in general from the experiences of survivors, for example, the background of life, historical stages, and forms of sexual abuse that occurred to them. Besides, we carry out in-depth interpretations to clarify the victim's narrative to project the structure of the experience and how the victim understands cases of online sexual violence.

BL Story: Demands as a Sexy Photo Model. BL is a woman who works as an adult photo model in Jakarta. All their family and colleagues know that he works as a model. Having a sexy body, a beautiful face, and an energetic impression are the main assets of being a model of the middle and upper class. Starting her career in high school approximately five years ago, BL dreamed of 
becoming a famous professional model, like the Miss Universe Indonesia. Her interest in modeling and photography took her seriously, even took the time to explore her interests after graduating from high school by joining the film casting event. That expectation is a little pushing her to become a model now, including changing their orientation to become a sexy photo model.

When plunged into the world of modeling, BL has many good and bad experiences while undergoing a profession. For example, he has won several model awards at the regional-national level and has been the best candidate in the photography arena. However, it is not uncommon for BL to experience bad experiences with those around her, both expressions and direct actions that hurt her. As described below;

"Appearing in a seductive, hot, sexy style is always synonymous with the harmful, wrong, or bad world, although actually, my kingdom is right, they judge people from the words of others, that's the problem [...] many are disparaging, slandering or bully of various, yes, all look at the outside appearance, this is also because as a model I have to be sued with a sensual style, attract men and development outside now, but that is indeed the responsibility of the job as an adult photo model that is arguably professional, so just let others want to judge me like what, it's up to them, now I'm also focused on improving myself without judging them, and I also do not disturb their lives" (Interview with BL, March 4, 2020)

The views of the Indonesian people always place the work of the model as a moral deviation. The community is still confined by religious dogma and cultural values dressed in the archipelago so that it cannot accept sensual poses as in western culture. Raw images that show the shape of the body with minimal dressing are complicated to be considered as usual in Indonesian society, despite the argument that it is an art form. Conversely, this condition backfires for BL when experiencing sexual violence some time ago. She was the party to blame because some people considered her to provoke someone's desire for sexual abuse. In fact, in reality, BL, which has long been a model, has never experienced such incidents of harassment. Only this time, she had suffered bad luck to experience severe trauma in life. 
"An unfortunate incident happened to me; I was humiliated and sorry about the event, initially as usual, without any problems, so there was no suspicion, but when on location, during a sudden briefing, it was awkward with the previous agreement [fashion problem] I tried to protest, but they didn't respond; finally I followed their wishes with positive thoughts [...] I did often wear open clothes, so everyone thought it was natural that she harassed me, especially with my work considered different compared to friends of the same age [...] now it was indeed a difficult time to convince everyone if I worked well, not guilty of this case, I am here the victim is not a perpetrator, and it is not a matter of dress, but their mentality is damaged to do this" (Interview with BL, March 6, 2020)

$\mathrm{BL}$ is a survivor of sexual violence committed by unscrupulous photographers. The damned action took place around the end of January in one of the famous hotels in West Jakarta. The abuse began at the first photo session, and it got worse after the photo process was over. The perpetrator carries out arbitrary actions by threatening to damage the popular victim so that their career as a model is destroyed. In this precarious situation, BL did not stand still; she fought against threats from which the perpetrators could escape.

However, the act of sexual assault that he received was still not over. In February 2020, she got a shipment of photos from a colleague who showed pictures of BL hot scenes from different angles, hidden and unfocused. The perpetrator seems to have prepared a hidden camera in certain parts of the room. Some photos show being in the locker room (bathroom), and the rest are incidents of acts of sexual violence committed by perpetrators on victims.

"I will show a lot of photos later, at most when the photo scene, everything is recorded; some are not focused, but I drop even more when I know that my photos are shared to be sold on the fake account [perpetrators], so the perpetrators active in the social media account, then the photos that he stole secretly with models were uploaded to attract buyers who saw, who was interested in the pictures of the model, for example, woman A, the buyer had to pay, then given an address to download [...] the photo problem he could not say anything, but if sold online with that pose without my knowledge becoming a big problem, I've reduced the photo offer, besides because the pandemic, I still traumatized [...] now I have also begun asking my followers to report the accounts used and asking the hacker service to delete everything; hopefully, all will end soon" (Interview with BL, March 6, 2020) 
Looking at the problem of BL experience, it can seem that anyone can commit sexual violence. Besides, image-based sexual abuse has the potential in the world of modeling because the photos can be consumed by the public freely, especially on victims' social media accounts. According to Bruce (2016), social media builds the freedom of women to present their work and lives, but the online sphere risks the threat of violence against women. In the BL case, a sensual photo was first made by the perpetrator with the victim's professional approval as a model but instead led to criminal acts because it was distributed online without the victim's consent (Salter and Crofts 2015).

Actors' actions, on the other hand, have carried out online pornography transactions through the trading of sexual photos on social media. In short, pornographic production has moved into a lucrative illegal business and has become an integral part of sexual violence (Bergen and Bogle 2000; DeKeseredy and Corsianos 2016; Jensen 2007). Internet growth support can globalize access to pornographic content that demeans women and other vulnerable groups in an online or offline environment. Crime results in the form of image and video media are quickly distributed to millions of people in just seconds, so digital technology has facilitated the distribution of pornographic content, which will have implications for increasing the number of online sexual violence in modern society (DeKeseredy and Corsianos 2016).

JM Story: Fooled by the Model Agency. The next experience is the story of JM, a final-year student at a private tertiary institution located in Jakarta. Now, she is busy preparing her thesis research for university graduation requirements. She said that her life had begun to be independent, about a year more, because of the side job of being a model. JM's work in modeling has just been occupied by JM when she migrated from her hometown, one of the cities in East Java. The purpose of education that initially took her to migrate out of town turned out to be hampered by economic needs and introduced her to the modeling world some time ago. Through someone's invitation on social media and friends from other majors on one campus, finally, JM was tempted and encouraged the desire to freelance as a model, even though, in the beginning, she was worried about the fear of being fooled.

Having an ideal and charming stature makes her successful in work. Sense of objection and fear, the longer it can be remedied by the payment it receives 
after becoming a photo model. The necessities of life while living in Jakarta can be fulfilled from the hard work of working as a photo model. Seeing their condition now, JM feels that the modeling world is indeed her talent; she likes it. Many photographers and modeling agencies offered to work permanently, but JM refused because he thought the experience was not much compared to professional colleagues. JM was not too famous compared to BL.

"First, know this from a college friend, hesitated initially, but I made a lot of requirements, worried about fraud [...] I certainly do because of money; parents are starting to be difficult because there are still younger siblings at home who will be graduating from high school, and their dependents are quite a lot, so I have to work and be independent all this time [...] I'm grateful that the conditions are now slightly improved, but a career as a model is only part-time, not always a model, there are still better jobs, especially my experience is still a bit" (Interview with JM, April 11, 2020)

However, the model profession that JM is currently undergoing experiences serious obstacles, to the point of making her despair. The problem is the case of online sexual violence that just happened to her, precisely in March. The traumatic pressure was clearly illustrated when JM described the incident in detail. She said that there was no material loss to the experience, but she was slightly under psychological stress. The hot photo scenes taken by a group of fictitious agencies were spread online on several social media. Job offers by photo agencies (perpetrators) through social media accounts Instagram victims initially did not show any strangeness. The pandemic, which reduced employment in line with JM's declining financial capacity, was the main reason for making her quickly accept the offer given by the perpetrators.

"During this corona, the work is quiet, daily needs are many, and nothing can be expected besides work, so when there is an offer, I accept it, even though with fear of corona spreading high, my mind as long as I get money [... ] was devastated if I knew the case, I had been active on the same social media, and suddenly many people sent messages; my photos had already spread on social media, my body immediately went limp and cried, why would anyone have the heart to harm I [...] This experience is indeed unfortunate, I do not know if the photo spread; moreover, I was not paid according to the agreement at the beginning, so I suffered a loss twice" (Interview with JM, April 11, 2020) 
Not only the psychological pressure from the experience of online sexual violence, but JM also said that the agency fooled her. The perpetrators did not pay anything to them because all models must go through the test shoot process. All poses and clothing are unilaterally determined by the actors (many photographers) without accepting the opinion of the model. As a result, the resulting image seems very vulgar because it is forced to take nude photos. The perpetrators, once again, convince all models not to share pictures that they have made because it is only a test shoot condition. After the photo session, all the models did not receive the money agreed upon, but they were invited to a club in the South Jakarta area. The perpetrators ignored those who protested. Even JM and other model colleagues offered to sell to masher men; human trafficking occurs, which leads to prostitution. Some friends decide to run away, and some others are forced to accept the invitation of the perpetrator. However, JM did not pay too much attention to the case. He considered that all could be lessons in the future, so be careful.

However, her disappointment culminated when he found out that vulgar photos spread on social media. The perpetrators denied the reason the perpetrator promised not to publish the results of the test shoot to the public. After a more indepth search, it turns out that the fictional model agency that exploits JM has an online prostitution syndicate and the sale of pornography. They often carry out transactions of pictures and videos of victims of models persuaded by test shoots. Actors facilitate pornographic consumers with the Line, Telegram, and Twitter groups. Consumers can contact you directly, make price and payment agreements, and later enter as an online member so they can enjoy all the results of harassment of the model. Social media eventually developed into a space for gender inequality dominated by male intervention, burying emancipatory technology (Shokooh Valle 2020).

The implications of JM's experience affect the conditions of life until now. The problem is that many men find their social media accounts, so JM experiences further sexual violence. The pictures are seen by the masher men who become the lighters for them to act sexting. The terminology of sexting may be relatively new to some people. Still, it can be interpreted as a practice of visual sexual harassment that involves the experience of sharing photos, videos, and porn 
Jat miko: Covid-19, Harassment and

Social Media: A Study of Gender-Based

Violence Facilitated by Technology

During the Pandemic

texts through technological devices (Brown, Keller, and Stern 2009; Crimmins and Seigfried-Spellar 2014; Hasinoff 2012).

Her life was interrupted by a message on social media accounts that led to harassment, sexual overtones, and being rated as a prostitute. The tendency of sexting indeed allows a woman to be humiliated as a prostitute because of a nude picture. In some instances, online violence through sexting extends to more dangerous forms of sexual abuse, leading to informal meetings and rape (Handyside and Ringrose 2017; Noll et al. 2009; Ricciardelli and Adorjan 2019). Therefore, JM blocks rogue accounts that send sexual messages, then tries to remove its social media applications to calm down. Next, she plans to change the name of the account with a new character or create an old account and create a new version different from before (see Franks 2012; Gumbus and Meglich 2013).

MP Story: Personal Relationships and Self-Esteem. MP, an 18-year-old teenage girl, grew up in a modest family who lives in a village in the Surabaya area, East Java. As before, MP is the daughter of a broken-home family. She lives with her mother, who works as a household assistant. The loss of a father figure to be a companion in her life makes her lonely. The social background prompted her to look for a man more mature than her to be a partner, later called dating. Establishing a relationship with a man who has a different six years of age does not discourage her when her school friends underestimate her. According to JM's statement, she did not feel that dating for more than a year. The relationship is harmonious, happy, loyal, and interconnected with trust.

However, the older the age of their dating relationship, many problems occur with their partners. Her involvement began to show boredom, so RE, the boyfriend of MP, began to be challenging to meet and stay away from without apparent reason. On the other hand, RE also experienced a drastic change because it often submitted unusual requests. If they play or enjoy the atmosphere of Saturday night, the tradition of Indonesian youth to have fun all night long, RE always requests to have sex as a sign of the seriousness of the two. Not infrequently, RE performs unpleasant treatments and unwanted body touches, but MP just falls silent without providing any resistance because it is considered normal in courtship relationships. 
"The way he got more and more brutal, love and affection were always compared to what I gave, just changed from before, but I could not refuse; I love him, so I want to even though it was terrible [...] RE once asked me to PAP photos (Post A Picture) naked, showing breasts, he sent pictures of her genitals, every time I video call the night also forced without wearing clothes [...] news from her friend also other women often go out with her, even though every day he always says if busy working, he can't go with me, except for holidays" (Interview with MP, June 23, 2020)

The use of internet access has developed rapidly and has become a part of daily life as a whole, both for work and leisure activities (Hughes et al. 2012; Reyns, Henson, and Fisher 2011). Such cases also show that adolescent girls become very vulnerable in using social media. Images are arranged directly by the victim, choose certain sensual positions, and are very clear because the photo shoot is done independently with awareness (see Butler 2007). Communication of text and voice messages can persuade them to provide their sexual images. Sexual image content calls girls to present themselves as sexually attractive online by uploading provocative photos on social media or through applications (Vandenbosch and Eggermont 2012). Even the online context facilitates adolescent sexual experiences to engage in sexting. Recent studies suggest that $13 \%$ to $17 \%$ of adolescents are sexually provoked during sexual exploration to allow exploitative sexual relations in women and public concerns (Maas, Bray, and Noll 2019; Titchen et al. 2019).

Sexual violence by RE against MP is increasing when they get a chance to do deviant sexual acts. In the end, MP couldn't stand the sexual abuse of her boyfriend and chose to end their relationship. However, RE firmly refused to persuade, but MP had been serious about not dating. Finally, in April 2020, they decided to avoid each other without building communication links as before. 
"I cannot stand anymore with his behavior, every night asking for photos with vulgar; he had no heart; his kindness was only at the beginning of our relationship, every meeting he touched me hard, making intimate contact that I didn't like, the forced sexy actions continuously made me bored and not free [...] I was traumatized; the video submissions requested every day turned out to be exchanged and shared with friends and other people; I was very disappointed in him; I'm like a prostitute who has no pride in front of people, people - people already know the real me [while crying], they see my photo, not just anyone here, but everywhere can see my picture, I'm afraid of my future, what about my mother who struggled all this time, not to mention my husband when I found out if he can accept my condition, this is the worst day of my experience" (Interview with MP, June 23, 2020)

When the case became more widespread, MP demanded accountability from the perpetrator. However, RE argued that he did not carry out the incident, but the perpetrator's cellphone was lost, and he considered the inventor who spread the photo. Not trusting the ex-boyfriend's argument, MP then searched all the luggage of the perpetrators. The victim obtains a mobile phone that the perpetrator uses; then MP destroys the mobile phone in front of many people. While she did not receive a direct response from the abuser, MP stated that she was a little relieved because the device that stored all of her dirty images could destroy.

Looking at cases of online sexual violence that began to exist in dating relationships, probing victims' stories illustrates the danger of intimate relations to violence. The closeness between the victim and the perpetrator provides an excellent opportunity to repress the victim; through physical, visual, and verbal actions. All acts of personal relations, especially dating, experienced by women can turn into threats, exploitation, and assault to undermine or eliminate the subject's ability to control partners (Connell 1995; Kelly 1988).

In this case, we see the motive for JM's ex-boyfriend's action as porn revenge, which implies the spread of non-consensual pornographic content through digital networks. Support of the sexual harassment subculture on social media was created and managed by a group of men to influence men's perceptions of hurting their ex-boyfriends by portraying image-based sexual violence (Salter and Crofts 2015). However, DeKeseredy and Schwartz (2016) noted that revenge has many perpetrators' motives, makes money, jokes, or for no reason at all, but has the same goal at the expense of profound loss to the victim. 
AC Stories: Online Threats to the Real Body. The survivors' narrative continues with an interview with a young woman who has various life experiences. Her teenage years passed with many life challenges, ranging from family, economic problems and dating relationships. After graduating from school two years ago, in 2018, economic conditions forced her to work. Both parents cannot fulfill the ideals of continuing education to the undergraduate level. In the transition to looking for work, air conditioners were accepted at a grocery and cake shop as shop assistants. However, it did not last long, almost two months, because he felt the salary received was not worth the hard work. He then opened an online business while looking for a job again. In 2019, AC finally accepted an offer from an old friend at her school to become a Sales Promotion Girl (later referred to as SPG), a well-known mobile phone brand in Indonesia.

In addition to opening an online shop, $\mathrm{AC}$ said that he was very suitable to work as an SPG. While working as an SPG, he felt the job was a fun activity to make money without being tired and dirty. The days of her work passed well until one day, meeting a customer who would later become her lover, the initials HY. Their meeting was short, just getting acquainted and exchanging telephone numbers, then they proceeded via text messages on the WhatsApp application. After several months of personal communication, the AC invited us to meet and eat at a famous cafe in Yogyakarta. Starting from that meeting, HY then expressed her feelings for $\mathrm{AC}$ to have a relationship.

"If traced from behind, all the work I've tried, starting from ordinary work until now I work as an SPG, finally I also started my luck online, looking for something cheap because I didn't have significant capital [...] at that time meeting with friends school in a cafe, he offered a job as an SPG; finally, I started to try it [...] SPG I think is the most delicious job in terms of finance; the same is not too big, but we don't need to spend energy, just talk to get buyers, plus always appearing clean [...] during that work I also met my ex-boyfriend" (Interview with AC, March 19, 2020)

The dating period, in the beginning, was beautiful and romantic, said AC. Lots of togetherness, both in joy and sorrow. AC explains her dating experience often gets simple surprises in the form of gifts and pleasant attention from her lover. However, there are shrimp behind the stone, and good intentions turned out to have a specific purpose in the AC. Boyfriends he knows are very overprotective and always ask for sexy photos every time they go to sleep. Video calls became 
HY's means of online sexual violence to satisfy his desires. AC sometimes obeys the lover's request to do something without any suspicion of the couple. AC's life has fallen into an object of violence perpetrated by her boyfriend, even through intimate relationships.

"If you just explained that the act was sexting, it means I did everything; it's almost every day like that; I get bored; why does he ask for pictures, videos, and live video calls that lead to that action? What will my boyfriend make if I menstruate? He always asks for nude photos; it could also be the opposite [...] for example, I don't want video calls or give a picture, he immediately gets angry and just disappears, so it's difficult for me in this relationship [...] he thinks it's natural in courtship, only recognized as a ration because his friend does the same to his girlfriend" (Interview with AC, March 19, 2020)

The longer the relationship with a partner becomes unhealthy, the more fights lead to infidelity problems. The argument of mutual accusation between the victim and the perpetrator occurs continuously; neither side succumbs. The tense of mounting problems then caused the two to cut off communication at the end of 2019 and agreed to end in January 2020. Feelings of regret occur; according to her, all have been given, and have never made a mistake. AC's regrets have not ended yet, coupled with a sense of disappointment and anger because her exboyfriend has been sending vulgar pictures shipments without the knowledge of the victim.

"My suspicions have been right, and he has spread my vulgar pictures to Twitter with an anonymous account; he also made a status on WhatsApp when we broke up, even though my face was covered with stickers or blurred, but everyone will know it [...] I also asked for responsibility because I dishonored the photo that I had given [...] the reasons were varied, which was clear had fled, disappeared, the office where he worked told me if I had been out a long time ago, the home address that given was also a fake, such a loser sexual predator" (Interview with AC, March 19, 2020)

Since that incident, AC began to move away from people around, and social media activity was reduced. February to March 2020 became a dark period in her life. Deep trauma made the air conditioner change drastically. Her parents were also astonished because he did not tell of the problems that had occurred. Like the previous changes, she also stated that the changes continued in everyday 
appearance, using the hijab. Changes must occur so that people who have seen pornographic photos on social media do not precisely know them.

"I must be a new self, not like before, now I open a new page, trying to get up with a different physique from the photo, appearance, lifestyle, and all I change; I do not want the incident to repeat itself, I am indeed a rogue who has never walked on the right path, but this problem makes me very embarrassed, depressed, and open my heart to change [...]this change is still disturbing because I have not dared to tell my parents, they do not know what this case is, I do not want to add my mother's problem, she must have been disappointed" (Interview, with AC, March 19, 2020)

The shadow of online sexual violence that has occurred continues. AC told in a low voice, suggesting fear and psychological distress as survivors of sexual abuse. The closure of the victim, not to say the case to the family, has resulted in sexual violence in the real world.

"This problem also still has a domino effect because my age siblings know my picture, and he has found the image on social media; his behavior certainly is not much different from my ex-boyfriend's predatory sexual; he threatened to tell my parents so that I immediately get punishment in the family, I was scared until now [AC tears flowing], as a way to keep her mouth shut so as not to tell my mother, she always demands that I have sexual relations without anyone's knowledge, she raped me a few days ago because I refused her invitation, but I will be honest as soon as possible in my parents, I want to be me again, live simply and not be a means of venting the desires of immoral men" (Interview, with AC, March 24, 2020)

The AC statement above is a new acknowledgment that was not obtained in the previous interview. Courage to express the problem, according to AC, because it expected that no victims of sexual violence would experience harassment simultaneously in a short time. He confirmed that the threat of sexual abuse was very high on social media. Still, a victim's sexual violence experience was even more dangerous when not voiced to the family or the public. The speed of the internet in distributing non-consensus photographs on social media, through posting, liking, retweeting, and reposting, has become a significantly dangerous form of online sexual violence (Dodge 2016; Dodge and Spencer 2018; Powell 2010).

The AC narrative reminds Vitis and Gilmour (2017), who explain the impact of sexual violence is not only detrimental to the victim's socialpsychological but can create other actors who attempt to discipline the victim 
Jat miko: Covid-19, Harassment and

Social Media: A Study of Gender-Based

Violence Facilitated by Technology

During the Pandemic

through shame and fear. Online harassment is transforming into a threat and form of sexual violence in the real world. Online sexual harassment will always be the target of mistakes because of the labeling and stigmatization of the community. The body is always assumed to be an object due to the objectification of the results of images scattered online to make victims more likely to become victims of violence again (Titchen et al. 2019).

\section{c. Technology-Facilitated Sexual Violence and Dromology in Social Media}

Based on the findings in the field, we see that the Indonesian context, which is currently in the COVID-19 pandemic, has changed the habits of individuals in society, which initially prioritized physical presence for digital activity. Correspondingly, the COVID-19 outbreak is calling on the population to carry out electronic practices that lead to increasing the usage of the Internet internet, including for jobs, education, and efforts to alleviate boredom during an individual quarantine. Men have a higher chance of surfing on social media. Under these conditions, women's vulnerability to gender-based violence will go hand in hand with social media (see Arafa and Senosy 2017). Online virtual space is transformed into a dangerous risk space where the presence of women must be excluded and restricted if they want to stay safe.

Another concern related to the continued existence of the COVID-19 pandemic in Indonesia, which is not finished, further worsens online gender-based violence. The opinion Aolain (2011) argues that women and girls become increasingly vulnerable to abuse when the social order is destroyed, along with extraordinary circumstances that disrupt the rhythm of daily life during and after post-disaster (Fisher 2010). This confirms that cases of gender-based violence, especially domestic violence and online sexual violence, will continue to increase significantly during the COVID-19 pandemic in Indonesia. The socio-economic impact of quarantine at the same time triggered by the high intensity of the use of social media makes it possible for the closest people or online sexual predators to target women to be their target (Henry and Powell 2014).

In particular, based on the experience of all victims, social media in the form of Twitter became the primary means of providing a place for online sexual violence. The speed tendency on Twitter facilitates many types of transactions and 
interactions used for various types of online sexual harassment. For example, consuming pornographic content, sharing photos/videos that refer to revenge online, advertising members in a porn group, and being involved with collecting other pornographic content. As a social network that is easily accessible to the public, Twitter provides a vast and potential social networking space for spreading pornographic content, both from the results of sexting for revenge or deliberately selling pornographic works without consensus.

The change in the form of sexual violence online seems to be in line with Paul Virilio's thoughts, which describe the technology and basis for the formation of human experience. He focused on the science of speed, which is referred to as dromology. According to Virilio (1986), the concept of dromology is defined as the accumulation of knowledge relating to speed experiences (social, political, and economic acceleration) and, in particular, implications for compressed human life. The transmission of communication provided by modern technology in society causes a loss of direct presence and aspects of experience that are realized directly. In other words, the development of telecommunications technology can negate real space, crisis space representation, and world distortion (Virilio 2008).

In this case, social media as an online sexual violence facility increases the prevalence by involving and replacing other spaces to obtain more useful navigation. The reality of Indonesian society, which began to be technocratic, and the high number of users of social media correlated with the reduction of gestures to digital reality. Online sexual violence is finally possible when faced with duplication of fact, that virtual reality (pictures/videos) and real reality (individual activities entering social media) double relationships to become a reality. Space and time entirely collapse because it is realized in digital space. Digital visualization then places individuals in a position of inertia that radically changes our relationship with the real world (Virilio 2000a).

Ultimately, the dimension of sexual violence transformed into an earthly absence that eliminates space and time. The culture of contemporary technocratic societies is continuously immersed in digital space, born in internet connectivity that provides intangible simulations. The most apparent form of threat of genderbased violence in the future is online-based violence because it is exclusively taken over by teletopical persistence, the negation of time and space (Virilio 1997). All human activities, especially sexual abuse, tend to be transferred into 


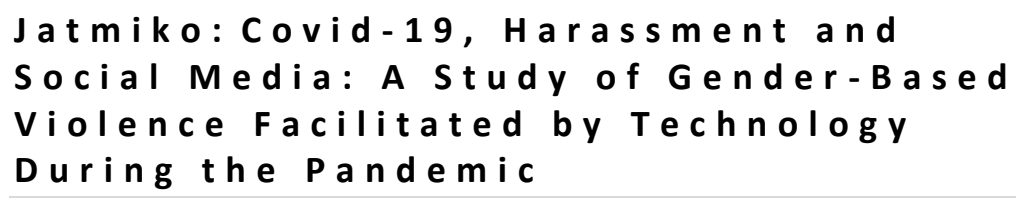

communication technology to produce new supremacy about real-time and real space (Virilio 2000a, 2000b).

Besides, the transition to social media redefines the subjectivity of individuals who form new experiences of visualization of space and time because they have eliminated geographical areas. The condition of contemporary social media in society then increasingly urges individuals to address technology risks personally, and victims of online sexual violence are expected to manage their crime risks when entering the virtual realm (Backe, Lilleston, and McCleary-Sills 2018; Garland 2001; Karaian 2013). An ideological shift towards independent responsibility can represent that social media, as part of virtual reality, simplifies optical density from real-world representations that are very risky. Humans try to enter virtual space by simplifying challenges through the contraction of time and distance. They prioritize the speed of technology transmission over social, economic, and political impacts (Virilio 2000b).

\section{CONCLUSION}

This article has explored harassment by looking at two perspectives (online gender-based violence and dromology) to provide a better understanding of the phenomenon of technology-facilitated violence since the spread of the coronavirus pandemic in Indonesia. We state that technological advances, the high number of social media users, and the increasing intensity of social media during the COVID-19 epidemic have further exacerbated the phenomenon of online genderbased violence. The results of this study reveal that many women are victims of offline sexual violence and continue to be victims of online violence. Cyberspace which has high-speed acceleration has been shrouded by hegemonic masculinity by playing in the authority of technology; become a vehicle for creating the online sexual violence revolution of today. The summarization of distance and time through technology then becomes a strategic reality that has consequences for victims of online sexual violence because it can provide repeated attacks on social media networks; the victim becomes a pole of inertia. However, online harassment is a complex combination of technical elements and socio-cultural 
practices, so the characteristics of gender-based violence are not always created by technology but rather "facilitated by the use of new technology".

\section{REFERENCES}

Aolain, Fionnuala Ni. 2011. "Women, Vulnerability and Humanitarian Emergencies." Michigan Journal of Gender \& Law 18(1):1-23. https://doi.org/10.2139/ssrn.1611818

Arafa, Ahmed, and Shaimaa Senosy. 2017. "Pattern and Correlates of Cyberbullying Victimization among Egyptian University Students in BeniSuef, Egypt." Journal of Egyptian Public Health Association 92(2):107-15. https://doi.org/10.21608/EPX.2018.8948

Backe, Emma Louise, Pamela Lilleston, and Jennifer McCleary-Sills. 2018. "Networked Individuals, Gendered Violence: A Literature Review of Cyberviolence." Violence and Gender 5(3):135-46. https://doi.org/10.1089/vio.2017.0056

Barak, Azy. 2005. "Sexual Harassment on the Internet." Social Science Computer Review 23(1):77-92. https://doi.org/10.1177/0894439304271540

Barnes, Susan B. 2006. "A Privacy Paradox: Social Networking in the United States." First Monday $11(9 \quad$ SE-Articles). https://doi.org/10.5210/fm.v11i9.1394

Beech, Anthony R., Ian A. Elliott, Astrid Birgden, and Donald Findlater. 2008. "The Internet and Child Sexual Offending: A Criminological Review." Aggression and Violent Behavior 13(3):216-28. https://doi.org/10.1016/j.avb.2008.03.007

Bergen, Raquel K., and Kathleen A. Bogle. 2000. "Exploring the Connection Between Pornography and Sexual Violence." Violence and Victims 15(3):227-34. https://doi.org/10.1891/0886-6708.15.3.227

Brown, Jane D., Sarah Keller, and Susannah Stern. 2009. "Sex, Sexuality, Sexting, and Sexed: Adolescents and the Media." The Prevention Researcher 16(4):12-16.

Bruce, Toni. 2016. "New Rules for New Times: Sportswomen and Media Representation in the Third Wave." Sex Roles 74(7):361-76. https://doi.org/10.1007/s11199-015-0497-6

Burke, Sloane C., Michele Wallen, Karen Vail-Smith, and David Knox. 2011. "Using Technology to Control Intimate Partners: An Exploratory Study of College Undergraduates." Computers in Human Behavior 27(3):1162-67. https://doi.org/10.1016/j.chb.2010.12.010 


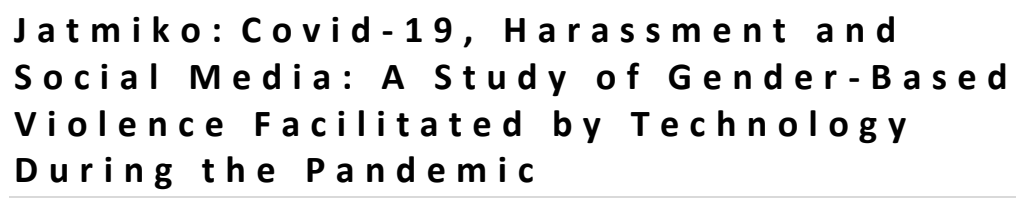

Butler, Judith. 2007. "Torture and the Ethics of Photography." Environment and Planning D: Society and Space 25(6):951-66. https://doi.org/10.1068/d2506jb

Connell, R. W. 1995. Masculinities. Berkeley: University of California Press.

Crimmins, Danielle M., and Kathryn C. Seigfried-Spellar. 2014. "Peer Attachment, Sexual Experiences, and Risky Online Behaviors as Predictors of Sexting Behaviors among Undergraduate Students." Computers in Human Behavior 32:268-75. https://doi.org/10.1016/j.chb.2013.12.012

Cuklanz, Lisa M. 2000. Rape on Prime Time: Television, Masculinity, and Sexual Violence. Philadelphia: University of Pennsylvania Press.

DeKeseredy, W. S., and M. Corsianos. 2016. Violence against Women in Pornography. New York: Routledge.

DeKeseredy, Walter S., and Martin D. Schwartz. 2016. "Thinking Sociologically About Image-Based Sexual Abuse." Sexualization, Media, \& Society 2(4):1-8. https://doi.org/10.1177/2374623816684692

Dodge, Alexa. 2016. "Digitizing Rape Culture: Online Sexual Violence and the Power of the Digital Photograph." Crime, Media, Culture: An International Journal 12(1):65-82. https://doi.org/10.1177/1741659015601173

Dodge, Alexa, and Dale C. Spencer. 2018. "Online Sexual Violence, Child Pornography or Something Else Entirely? Police Responses to NonConsensual Intimate Image Sharing among Youth.” Social \& Legal Studies 27(5):636-57. https://doi.org/10.1177/0964663917724866

Fisher, Sarah. 2010. "Violence Against Women and Natural Disasters: Findings From Post-Tsunami Sri Lanka.” Violence Against Women 16(8):902-18. https://doi.org/10.1177/1077801210377649

Franklin, Zak. 2014. "Justice for Revenge Porn Victims: Legal Theories to Overcome Claims of Civil Immunity by Operators of Revenge Porn Websites." California Law Review 102(5):1303-35. http://www.jstor.org/stable/24758167

Franks, Mary Anne. 2012. "Sexual Harassment 2.0." Maryland Law Review 71(3):655-704. 
Garcia-Moreno, Claudia, Henrica A. F. M. Jansen, Mary Ellsberg, Lori Heise, and Charlotte H. Watts. 2006. "Prevalence of Intimate Partner Violence: Findings from the WHO Multi-Country Study on Women's Health and Domestic Violence." The Lancet 368(9543):1260-69. https://doi.org/10.1016/S0140-6736(06)69523-8

Garland, D. 2001. The Culture of Control: Crime and Social Order in Contemporary Society. Oxford: Oxford University Press.

van Gelder, N., A. Peterman, A. Potts, M. O’Donnell, K. Thompson, N. Shah, and S. Oertelt-Prigione. 2020. "COVID-19: Reducing The Risk of Infection Might Increase the Risk of Intimate Partner Violence." EClinicalMedicine 21:1-2. https://doi.org/10.1016/j.eclinm.2020.100348

Ging, Debbie, and Eugenia Siapera. 2018. "Special Issue on Online Misogyny." Feminist Media Studies 18(4):515-24. https://doi.org/10.1080/14680777.2018.1447345

Gumbus, A., and P. Meglich. 2013. "Abusive Online Conduct: Discrimination and Harassment in Cyberspace." Journal of Management Policy and Practice 13(5):47-56.

Gundersen, Kristin K., and Kristen L. Zaleski. 2020. "Posting the Story of Your Sexual Assault Online: A Phenomenological Study of the Aftermath." Feminist Media Studies 1-13. https://doi.org/10.1080/14680777.2019.1706605

Handyside, Sarah, and Jessica Ringrose. 2017. "Snapchat Memory and Youth Digital Sexual Cultures: Mediated Temporality, Duration and Affect." Journal of Gender Studies 26(3):347-60. https://doi.org/10.1080/09589236.2017.1280384

Hasinoff, Amy Adele. 2012. "Sexting as Media Production: Rethinking Social Media and Sexuality." New Media \& Society 15(4):449-65. https://doi.org/10.1177/1461444812459171

Henry, Nicola, Asher Flynn, and Anastasia Powell. 2015. "The Promise and Paradox of Justice." Pp. 1-17 in Rape justice: Beyond The Criminal Law, edited by A. Powell, N. Henry, and A. Flynn. New York: Palgrave Macmillan. https://doi.org/10.1057/9781137476159.0005

Henry, Nicola, and Anastasia Powell. 2014. "Beyond the 'Sext': TechnologyFacilitated Sexual Violence and Harassment against Adult Women." Australian \& New Zealand Journal of Criminology 48(1):104-18. https://doi.org/10.1177/0004865814524218 


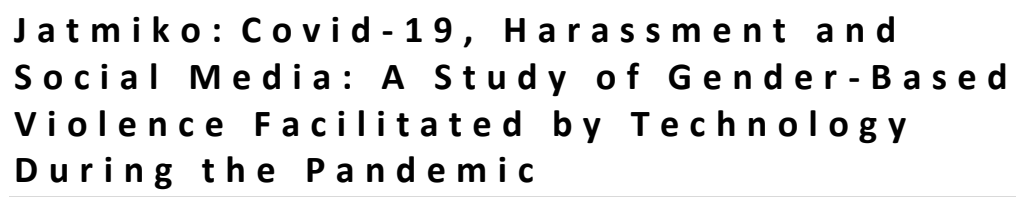

Henry, Nicola, and Anastasia Powell. 2015. "Embodied Harms: Gender, Shame, and Technology-Facilitated Sexual Violence." Violence Against Women 21(6):758-79. https://doi.org/10.1177/1077801215576581

Henry, Nicola, and Anastasia Powell. 2016. "Sexual Violence in the Digital Age: The Scope and Limits of Criminal Law." Social \& Legal Studies 25(4):397418. https://doi.org/10.1177/0964663915624273

Henry, Nicola, and Anastasia Powell. 2018. "Technology-Facilitated Sexual Violence: A Literature Review of Empirical Research.” Trauma, Violence, \& Abuse 19(2):195-208. https://doi.org/10.1177/1524838016650189

Hughes, David John, Moss Rowe, Mark Batey, and Andrew Lee. 2012. "A Tale of Two Sites: Twitter vs. Facebook and the Personality Predictors of Social Media Usage." Computers in Human Behavior 28(2):561-69. https://doi.org/10.1016/j.chb.2011.11.001

Jane, Emma A. 2014. "“Your a Ugly, Whorish, Slut."” Feminist Media Studies 14(4):531-46. https://doi.org/10.1080/14680777.2012.741073

Jane, Emma A. 2018. "Gendered Cyberhate as Workplace Harassment and Economic Vandalism." Feminist Media Studies 18(4):575-91. https://doi.org/10.1080/14680777.2018.1447344

Jensen, R. 2007. Getting off: Pornography and the End of Masculinity. Cambridge: South End Press.

John, Neetu, Sara E. Casey, Giselle Carino, and Terry McGovern. 2020. "Lessons Never Learned: Crisis and Gender-based Violence.” Developing World Bioethics 20(2):65-68. https://doi.org/10.1111/dewb.12261

Kappler, Karolin Eva. 2012. Living with Paradoxes: Victims of Sexual Violence and Their Conduct of Everyday Life. Germany: VS Verlag für Sozialwissenschaften.

Karaian, Lara. 2013. "Policing 'Sexting': Responsibilization, Respectability and Sexual Subjectivity in Child Protection/Crime Prevention Responses to Teenagers' Digital Sexual Expression.” Theoretical Criminology 18(3):28299. https://doi.org/10.1177/1362480613504331

Kavanagh, Emma, and Lorraine Brown. 2019. "Towards a Research Agenda for Examining Online Gender-Based Violence against Women Academics." Journal of Further and Higher Education 1-9. https://doi.org/10.1080/0309877X.2019.1688267 
Kelly, Liz. 1988. Surviving Sexual Violence. Cambridge: Polity Press.

Klein, Jessie. 2005. "Teaching Her a Lesson: Media Misses Boys' Rage Relating to Girls in School Shootings." Crime, Media, Culture 1(1):90-97. https://doi.org/10.1177/1741659005050245

Knaul, Felicia Marie, Flavia Bustreo, and Richard Horton. 2020. "Countering The Pandemic of Gender-Based Violence and Maltreatment of Young People: The Lancet Commission." The Lancet 395(10218):98-99. https://doi.org/10.1016/S0140-6736(19)33136-8

Kowalski, Robin M., and Susan P. Limber. 2007. "Electronic Bullying Among Middle School Students." Journal of Adolescent Health 41(6):S22-30. https://doi.org/10.1016/j.jadohealth.2007.08.017

Lewis, Ruth, Michael Rowe, and Clare Wiper. 2016. "Online Abuse of Feminists as An Emerging Form of Violence Against Women and Girls." The British Journal of Criminology 57(6):1462-81. https://doi.org/10.1093/bjc/azw073

Litchfield, Chelsea, Emma Kavanagh, Jaquelyn Osborne, and Ian Jones. 2018. "Social Media and the Politics of Gender, Race and Identity: The Case of Serena Williams." European Journal for Sport and Society 15(2):154-70. https://doi.org/10.1080/16138171.2018.1452870

Maas, Megan K., Bethany C. Bray, and Jennie G. Noll. 2019. “Online Sexual Experiences Predict Subsequent Sexual Health and Victimization Outcomes Among Female Adolescents: A Latent Class Analysis." Journal of Youth and Adolescence 48(5):837-49. https://doi.org/10.1007/s10964-019-009953

Mahase, Elisabeth. 2020. "Covid-19: EU States Report 60\% Rise in Emergency Calls about Domestic Violence." BMJ 369:m1872. https://doi.org/10.1136/bmj.m1872

Marwick, Alice E., and Ross Miller. 2014. "Online Harassment, Defamation, and Hateful Speech: A Primer of the Legal Landscape Recommended Citation." Fordham Center on Law and Information Policy Report No. 2 1-75. https://ssrn.com/abstract=2447904

Mazza, Marianna, Giuseppe Marano, Carlo Lai, Luigi Janiri, and Gabriele Sani. 2020. "Danger in Danger: Interpersonal Violence during COVID-19 Quarantine." Psychiatry Research 289:113046. https://doi.org/10.1016/j.psychres.2020.113046

McCormick, Naomi B., and John W. McCormick. 1992. "Computer Friends and Foes: Content of Undergraduates' Electronic Mail." Computers in Human Behavior 8(4):379-405. https://doi.org/10.1016/0747-5632(92)90031-9 


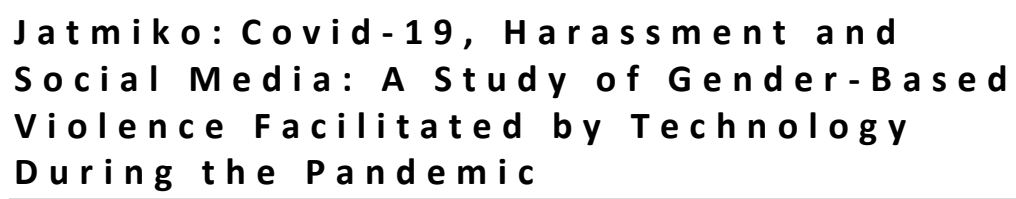

Mena-Rodriguez, Esther, and Leticia-Concepción Velasco-Martínez. 2017. "Gender Violence and Social Networks in Adolescents. The Case of the Province of Malaga." Procedia - Social and Behavioral Sciences 237:4449. https://doi.org/10.1016/j.sbspro.2017.02.009

Miller, Beverly, and Jon C. Marshall. 1987. "Coercive Sex on the University Campus.” Journal of College Student Personnel 28(1):38-47.

Noll, Jennie G., Chad E. Shenk, Jaclyn E. Barnes, and Frank W. Putnam. 2009. "Childhood Abuse, Avatar Choices, and Other Risk Factors Associated with Internet-Initiated Victimization of Adolescent Girls." Pediatrics 123(6):e1078-83. https://doi.org/10.1542/peds.2008-2983

Ojanen, Timo T., Pimpawun Boonmongkon, Ronnapoom Samakkeekarom, Nattharat Samoh, Mudjalin Cholratana, Anusorn Payakkakom, and Thomas E. Guadamuz. 2014. "Investigating Online Harassment and Offline Violence among Young People in Thailand: Methodological Approaches, Lessons Learned." Culture, Health \& Sexuality 16(9):1097-1112. https://doi.org/10.1080/13691058.2014.931464

Powell, Anastasia. 2010. "Configuring Consent: Emerging Technologies, Unauthorized Sexual Images and Sexual Assault." Australian \& New Zealand Journal of Criminology 43(1):76-90. https://doi.org/10.1375/acri.43.1.76

Ramadhan, Bagus. 2020. "Data Internet Di Indonesia Dan Perilakunya Tahun 2020." Teknoia.Com. Retrieved July 22, 2020 (https://teknoia.com/datainternet-di-indonesia-dan-perilakunya-880c7bc7cd19).

Reyns, Bradford W., Billy Henson, and Bonnie S. Fisher. 2011. "Being Pursued Online." Criminal Justice and Behavior 38(11):1149-69. https://doi.org/10.1177/0093854811421448

Ricciardelli, Rosemary (Rose), and Michael Adorjan. 2019. “'If a Girl's Photo Gets Sent around, That's a Way Bigger Deal than If a Guy's Photo Gets Sent around': Gender, Sexting, and the Teenage Years." Journal of Gender Studies 28(5):563-77. https://doi.org/10.1080/09589236.2018.1560245

Rodríguez-Darias, Alberto Jonay, and Laura Aguilera-Ávila. 2018. "GenderBased Harassment in Cyberspace. The Case of Pikara Magazine." Women's Studies International Forum 66(January-February):63-69. https://doi.org/10.1016/j.wsif.2017.10.004 
Salter, Michael, and Thomas Crofts. 2015. "Responding to Revenge Porn: Challenges to Online Legal Impunity." Pp. 233-53 in New views on pornography: Sexuality, politics and the law, edited by L. Comella and S. Tarrant. Westport: Praeger.

Shade, Leslie Regan. 2007. "Contested Spaces: Protecting or Inhibiting Girls Online? BT - Growing Up Online: Young People and Digital Technologies." Pp. 229-47 in Growing Up Online: Young People and Digital Technologies, edited by S. Weber and S. Dixon. New York: Palgrave Macmillan US. https://doi.org/10.1057/9780230607019_15

Shariff, Shaheen, and A. DeMartini. 2015. "Defining the Legal Lines: EGirls and Intimate Images.” Pp. 281-306 in eGirls, eCitizens, edited by J. Bailey and V. Steeves. Ottawa: University of Ottawa Press.

Shokooh Valle, Firuzeh. 2020. "Turning Fear into Pleasure: Feminist Resistance against Online Violence in the Global South." Feminist Media Studies 1-18. https://doi.org/10.1080/14680777.2020.1749692

Titchen, Kanani E., Sofya Maslyanskaya, Ellen J. Silver, and Susan M. Coupey. 2019. "Sexting and Young Adolescents: Associations with Sexual Abuse and Intimate Partner Violence." Journal of Pediatric and Adolescent Gynecology 32(5):481-86. https://doi.org/10.1016/j.jpag.2019.07.004

Vandenbosch, Laura, and Steven Eggermont. 2012. "Understanding Sexual Objectification: A Comprehensive Approach Toward Media Exposure and Girls' Internalization of Beauty Ideals, Self-Objectification, and Body Surveillance." Journal of Communication 62(5):869-87. https://doi.org/10.1111/j.1460-2466.2012.01667.x

Virilio, Paul. 1986. Speed and Politics: An Essay on Dromology. New York: Semiotext(e).

Virilio, Paul. 1997. Open Sky. London: Verso.

Virilio, Paul. 2000a. Polar Inertia. London: SAGE Publications.

Virilio, Paul. 2000b. The Information Bomb. London: SAGE Publications.

Virilio, Paul. 2008. Negative Horizon. London: Continuum.

Vitis, Laura, and Fairleigh Gilmour. 2017. "Dick Pics on Blast: A Woman's Resistance to Online Sexual Harassment Using Humour, Art and Instagram." Crime, Media, Culture: An International Journal 13(3):335-55. https://doi.org/10.1177/1741659016652445

Websindo. 2019. “Indonesia Digital 2019: Media Sosial." Websindo. Retrieved July 21, 2020 (https://websindo.com/indonesia-digital-2019-media-sosial/). 
Williams, Matthew. 2006. Virtually Criminal: Crime, Deviance and Regulation Online. New York: Routledge.

Yar, Majid. 2005. "The Novelty of 'Cybercrime': An Assessment in Light of Routine Activity Theory." European Journal of Criminology 2(4):407-27. https://doi.org/10.1177/147737080556056

Zaleski, Kristen L., Kristin K. Gundersen, Jessica Baes, Ely Estupinian, and Alyssa Vergara. 2016. "Exploring Rape Culture in Social Media Forums." Computers in Human Behavior 63:922-27. https://doi.org/10.1016/j.chb.2016.06.036

Zhong, Linda R., Mark R. Kebbell, and Julianne L. Webster. 2020. “An Exploratory Study of Technology-Facilitated Sexual Violence in Online Romantic Interactions: Can the Internet's Toxic Disinhibition Exacerbate Sexual Aggression?" Computers in Human Behavior 108:1-10. https://doi.org/10.1016/j.chb.2020.106314 